\title{
Long-term efficacy of recombinant human growth hormone therapy in short-statured patients with Noonan syndrome
}

Insook Jeong, $\mathrm{MD}^{1}$, Eungu Kang, MD', Ja Hyang Cho, MD', Gu-Hwan Kim, PhD', Beom Hee Lee, MD', Jin-Ho Choi, MD', Han-Wook Yoo, MD, PhD ${ }^{1}$

${ }^{1}$ Department of Pediatrics, ${ }^{2}$ Medical Genetics Center, Asan Medical Center Children's Hospital, University of Ulsan College of Medicine, Seoul, Korea
Received: 14 September, 2015 Revised: 12 October, 2015

Accepted: 26 November, 2015

Address for correspondence: Han-Wook Yoo, MD, PhD

Department of Pediatrics, Asan Medical Center Children's Hospital, University of UIsan College of Medicine, 88 Olympic-ro 43-gil, Songpa-gu, Seoul 05505, Korea

Tel: +82-2-3010-3374

Fax: +82-2-473-3725

E-mail:hwyoo@amc.seoul.kr
Purpose: Noonan syndrome (NS) is characterized by short stature, heart anomalies, developmental delays, dysmorphic features, cryptorchidism, and coagulation defects. Several studies reported the short-term effects of recombinant human growth hormone ( $\mathrm{rhGH}$ ) treatment on the improvement of height. This study was performed to evaluate the long-term efficacy of rhGH in children with NS in Korea. Methods: This study included 15 prepubertal NS children who received $\mathrm{rhGH}$ subcutaneously at a dose of $50-75 \mu \mathrm{g} / \mathrm{kg} /$ day for 6 days a week for at least $>3$ years. Preand posttreatment data, such as height, weight, bone age, insulin-like growth factor 1 (IGF-1), and IGF binding protein 3 (IGFBP-3) levels, were collected every 6 months. Results: Chronologic age and bone age at the start of treatment were $7.97 \pm 1.81$ and $5.09 \pm 2.12$ years, respectively. Height standard deviation score (SDS) was increased from $-2.64 \pm 0.64$ to $-1.54 \pm 1.24$ years after 3 years $(P<0.001)$. Serum IGF-1 SDS levels were elevated from $-1.28 \pm 1.03$ to $-0.10 \pm 0.94(P<0.001)$. Height SDS was more increased in subjects without PTPN11 mutations compared to those with mutations after 3 years $(P=0.012)$. However, the other parameters, including bone age, IGF-1 SDS, and IGFBP-3 SDS, were not significantly different between patients with and without PTPN11 mutations.

Conclusion: Although this study included a relatively small number of patients, long-term rhGH therapy in NS patients was safe and effective at improving height, growth velocity, and serum IGF-1 levels, in accordance with previous studies. However, the meticulous monitoring of potential adverse events is still needed because of high dose of rhGH and preexisting hyperactivity of RAS-MAPK pathway. Patients with PTPN11 mutations demonstrated a decreased response to $\mathrm{rhGH}$ therapy compared to those without mutations.

Keywords: Noonan syndrome, Growth hormone, PTPN11

\section{Introduction}

Noonan syndrome (NS) is an autosomal dominant disorder with an estimated incidence of $1: 1,000$ to $1: 2,500$ live births ${ }^{1}$. It is characterized by short stature, distinctive facial appearance, congenital heart defects (most frequently pulmonary valve stenosis or hypertrophic cardiomyopathy), thoracic deformities, bleeding diathesis, and cryptorchidism ${ }^{2}$.

Tartaglia et al. ${ }^{3)}$ demonstrated that the causative gene of NS is PTPN11 on chromosome $12 \mathrm{q} 24.1$, encoding the protein tyrosine phosphatase, SHP-2, in $40 \%$ to $50 \%$ of cases. The other common causative genes of NS are SOS1 $(17 \%-28 \%)$ and RAF1 $(5 \%-17 \%)^{4-8)}$. Genes accounting for less than $5 \%$ of NS are KRAS, NRAS, and $B R A F^{8,9)}$. Other rare causes of NS are MEK1 and RIT1 mutations ${ }^{9,10)}$. Mutations in the SHOC2 and CBL genes were reported in Noonan-like syndrome with loose anagen hair $(\mathrm{NS} / \mathrm{LAH})^{7,11)}$. 
NS is a genetically heterogeneous disorder caused by up-regulated RAS-MAPK signaling, resulting in growth disturbances ${ }^{4}$. The RAS-MAPK cascade is activated in response to cytokines, hormones, and growth factors, and is a major mediator of early and late developmental processes, including morphology determination, organogenesis, synaptic plasticity processes, and growth ${ }^{5}$. SHP-2, a protein tyrosine kinase encoded by PTPN11, plays diverse roles in signal transduction via the RAS-MAPK pathway, such as growth hormone $(\mathrm{GH})$ receptor signaling in children with $\mathrm{NS}^{12)}$. Thus, short stature with delayed bone age is the most common clinical feature of $\mathrm{NS}^{13)}$, with a mean adult height below $-2 \mathrm{SDS}^{14)}$. Over the last 2 decades, recombinant human GH (rhGH) treatment has been reported to increase height SDS in NS patients without severe adverse events ${ }^{15)}$. Long-term rhGH therapy for about 4.2-11.8 years in NS has been reported to produce height gains varying from 0.6 to $2.0 \mathrm{SDS}^{16,17)}$.

Our group previously reported that 1 year of rhGH therapy significantly improved height SDS in NS patients and the response to rhGH therapy was not affected by PTPN11 mutations ${ }^{18)}$. However, the long-term efficacy and safety of rhGH therapy in NS patients has remained elusive. Thus, this study evaluated the effects of long-term treatment with rhGH in NS patients and the influence of mutations in RAS-MAPK pathway genes.

\section{Materials and methods}

\section{Subjects}

This study included 11 males and 4 females with NS who received rhGH therapy for at least 3 years. Mean duration of rhGH therapy was 4.9 years (range, 3.3-6.6 years). The diagnosis of NS was based on the van der Burgt criteria ${ }^{19}$. Baseline characteristics of the 15 subjects are shown in Table 1. Among the 15 children, 12 had congenital heart defects, including pulmonic stenosis (7 subjects, $46.7 \%$ ), ventricular septal defect (3 subjects, 20\%), patent ductus arteriosus (4 subjects, 26.7\%), atrial septal defect (2 subjects, 13.3\%), or right ventricular defect (1 subject, 6.7\%). Five of them had two or more congenital heart defects. Mutations in the PTPN11 gene were identified in 9 subjects $(60 \%)$. Mutations in SOS1 were identified in 2 children $(13.3 \%)$ and KRAS mutation in 1 child $(6.7 \%)$ (Table 1$)$. No mutations were identified in 3 of the subjects (20\%).

\section{Methods}

The rhGH (Norditropin; Novo Nordisk Pharma, Hellerup, Denmark) was administered at a dose of $50-75 \mu \mathrm{g} / \mathrm{kg} / \mathrm{day}$ for 6 days a week subcutaneously. The main outcome measures were height SDS, growth velocity $(\mathrm{GV})$, bone age, serum insulin-like growth factor 1 (IGF-1) SDS, and IGF binding protein 3 (IGFBP-3) SDS. The subjects' height and weight were measured at baseline and every 6 months. Height and weight were expressed as SDS based on normative data from Korean references ${ }^{20)}$. The complete blood count, routine chemistry, free T4, thyroid-stimulating hormone, IGF-1, and IGFBP-3 levels were measured at baseline and at 6-month intervals. IGF1 SDS and IGFBP-3 SDS were calculated based on normative data from the Korean reference ${ }^{21)}$. The subjects' bone age was determined annually using the Greulich-Pyle method ${ }^{22}$. Electrocardiogram and echocardiogram were carried out every 6 months.

Puregene DNA isolation kits (Gentra, Minneapolis, MN, USA) were used for genomic DNA extraction from peripheral blood leukocytes. The coding regions and intronic flanking

Table 1. Clinical and endocrinological characteristics of patients with NS at baseline

\begin{tabular}{|c|c|c|c|c|c|c|c|c|c|c|c|}
\hline No. & Sex & Age (yr) & $\mathrm{MPH}(\mathrm{cm})$ & Height SDS & Weight SDS & $\begin{array}{l}\text { Growth } \\
\text { velocity } \\
(\mathrm{cm} / \mathrm{yr})\end{array}$ & IGF-1 SDS & $\begin{array}{l}\text { IGFBP-3 } \\
\text { SDS }\end{array}$ & Heart anomaly & $\begin{array}{l}\text { Molecular } \\
\text { analysis }\end{array}$ & $\begin{array}{c}\text { Initial dose of rhGH } \\
(\mu \mathrm{g} / \mathrm{kg} / \text { day })\end{array}$ \\
\hline 1 & $M$ & 9.9 & 173 & -3.61 & -2.68 & 5 & -2.80 & -0.55 & VSD,PS & PTPN11 p.F285S & 69 \\
\hline 2 & M & 6.2 & 170 & -3.17 & -2.17 & 6 & -1.57 & -0.13 & PS, ASD, RVH & PTPN11 p.N308S & 62 \\
\hline 3 & M & 8.9 & 169 & -2.79 & -2.22 & 4 & -3.13 & -0.49 & PDA & PTPN11 p.N308D & 63 \\
\hline 4 & M & 6.1 & 176 & -2.69 & -4.42 & 5 & -1.95 & 0.01 & Normal & PTPN11 p.Y63C & 70 \\
\hline 5 & M & 7.3 & 167.5 & -2.74 & -1.91 & 6 & -2.58 & -0.51 & VSD & PTPN11 p.Y63C & 63 \\
\hline 6 & $F$ & 11.3 & 142 & -3.78 & -1.57 & NA & -0.22 & -0.03 & Normal & PTPN11 p.T21 & 55 \\
\hline 7 & $F$ & 10.4 & 165 & -2.01 & -2.18 & 4 & -1.64 & -0.68 & PS, ASD & PTPN11 p.E139D & 72 \\
\hline 8 & $F$ & 6.1 & 157 & -2.45 & -1.06 & NA & -0.80 & 0.82 & PS & PTPN11 p.N308D & 70 \\
\hline 9 & M & 9.8 & 173 & -1.97 & -1.74 & NA & -1.11 & -0.47 & PS & PTPN11 p.N308D & 50 \\
\hline 10 & M & 6.9 & 170.5 & -2.00 & -3.28 & 5 & -0.92 & -0.39 & VSD, PDA & sOS1 p.E433K & 73 \\
\hline 11 & M & 6.6 & 174.5 & -1.79 & -2.14 & 4 & -0.13 & -0.02 & PDA & None & 63 \\
\hline 12 & M & 7.2 & 171.5 & -2.20 & -1.56 & 4 & -0.36 & 0.43 & Valvar PS & None & 70 \\
\hline 13 & M & 9.3 & 179 & -2.22 & -1.93 & 4 & -1.66 & -0.07 & Normal & SOS1 p.R552G & 67 \\
\hline 14 & M & 7.9 & NA & -2.61 & -3.39 & 6 & -0.68 & -0.11 & Valvar PS & KRAS p.I36M & 66 \\
\hline 15 & $F$ & 5.7 & 158.5 & -3.51 & -7.23 & 4 & 0.29 & -0.10 & PA with VSD, PDA & None & 61 \\
\hline
\end{tabular}

NS, Noonan syndrome; MPH, midparental height; SDS, standard deviation score; IGF-1, insulin-like growth factor 1; IGFBP-3, IGF binding protein 3; rhGH, recombinant human growth hormone; VSD, ventricular septal defect; PS, pulmonary stenosis; ASD, atrial septal defect; $\mathrm{RVH}$, right ventricular hypertrophy; PDA, patent ductus arteriosus; NA, not available; PA, pulmonary atresia. 
regions of the PTPN11 (whole exons), SOS1 (whole exons), KRAS (exons 1 and 4), RAF1 (exons 7, 14, and 17), SHOC2 (exon 1), NRAS (exon 3), BRAF (exons 6, 11, and 16), and MEK1 (exon 3) genes were amplified by polymerase chain reaction with specific primers and directly sequenced using an ABI3130xl Genetic Analyzer (Applied Biosystems, Foster City, CA, USA).

\section{Statistical analysis}

The Friedman test was used to evaluate the effect of rhGH therapy. The Wilcoxon signed rank test was used to compare the changes between pre- and post-rhGH therapy. The relationships between genotypes of subjects and growth parameters, such as bone age, height SDS, GV, and serum IGF-1 and IGFBP-3 levels were assessed by the Mann-Whitney $U$-test. Statistical analyses were conducted using IBM SPSS Statistics ver. 21.0 (IBM Co., Armonk, NY, USA). $P<0.05$ was considered statistically significant.

\section{Results}

\section{Efficacy of rhGH therapy in children with NS}

The mean age at the start of treatment was $7.97 \pm 1.81$ years (range, 5.7 to 11.3 years). Height SDS, GV, and serum IGF-1 SDS levels were significantly increased after rhGH therapy (Table 2 ). Height SDS increased from $-2.64 \pm 0.64$, to $-1.54 \pm 1.24$, to $-2.13 \pm 1.08$, respectively, at the first, second, and third years of treatment $(P=0.005, P=0.003$, and $P=0.001$, respectively). GV during the first year of treatment was highest $(8.57 \pm 1.49 \mathrm{~cm} /$ yr). GV increased from $4.64 \pm 0.80 \mathrm{~cm} / \mathrm{yr}$ at baseline to $6.79 \pm 1.26$ and $6.41 \pm 1.54 \mathrm{~cm} / \mathrm{yr}$ at the second and third years $(P=0.001$ and $P=0.003$, respectively). Serum IGF-1 SDS significantly increased from $-1.28 \pm 1.03$ to $-0.10 \pm 0.94$ after 3 years $(P<0.001)$. Serum IGFBP-3 SDS changed from $-0.15 \pm 0.40$ to $-0.09 \pm 0.34$, which was not statistically significant $(P=0.074)$. Bone age increased from $5.09 \pm 2.12$ years to $9.42 \pm 2.15$ years after 3 years $(P<0.001)$. The bone age/chronologic age ratio increased from $0.62 \pm 0.13$ at the start of treatment to $0.68 \pm 0.15,0.79 \pm 0.1$, and $0.86 \pm 0.1$,
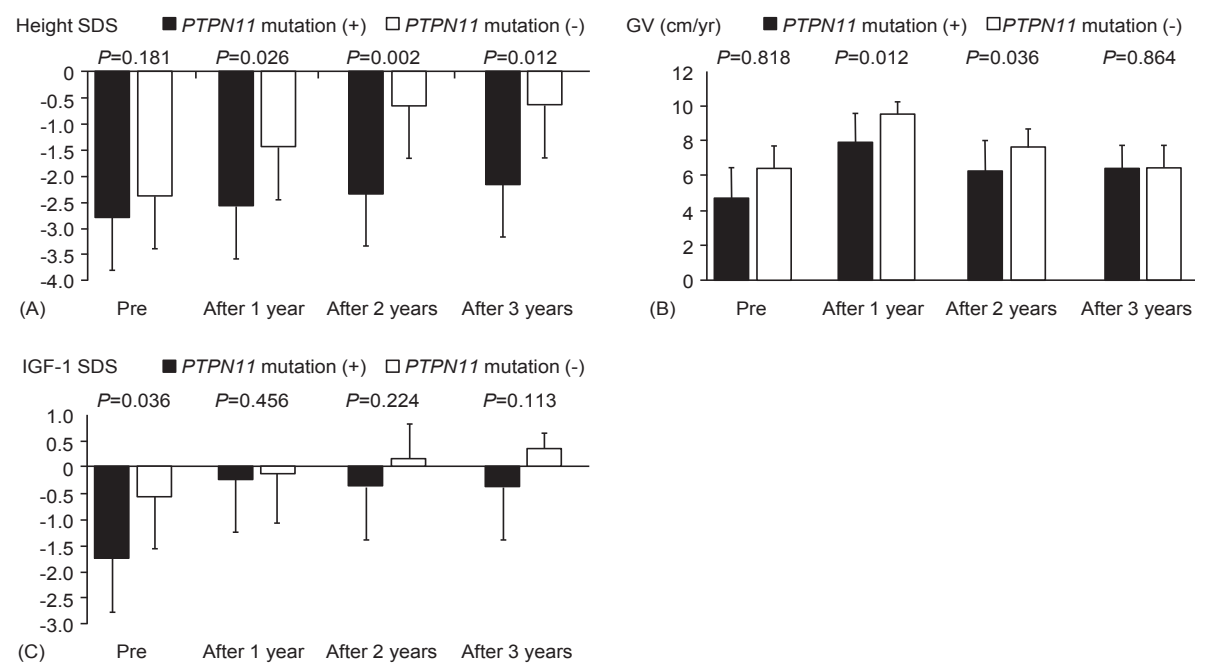

Fig. 1. Sequential changes of height SDS (A), GV (B), and IGF-1 SDS (C) during rhGH treatment in patients with Noonan syndrome with or without PTPN11 mutations. Mann-Whitney U-test was used to compare the response to rhGH therapy according to genotypes. $P$-values less than 0.05 were considered to be statistically significant. SDS, standard deviation score; GV, growth velocity; IGF-1, insulin-like growth factor 1; rhGH, recombinant human growth hormone.

Table 2. Clinical and endocrinological parameters during rhGH therapy

\begin{tabular}{lrrrrr}
\hline Variable & \multicolumn{1}{c}{ Baseline } & After 1 year & After 2 years & \multicolumn{1}{c}{ After 3 years } & \multicolumn{1}{c}{$P$-value } \\
\hline CA (yr) & $7.97 \pm 1.81$ & $8.63 \pm 1.32$ & $9.63 \pm 1.32$ & $10.63 \pm 1.32$ & NA \\
BA (yr) & $5.09 \pm 2.12$ & $6.31 \pm 2.48$ & $8.01 \pm 2.19$ & $9.42 \pm 2.15$ & $<0.001$ \\
Height SDS & $-2.64 \pm 0.64$ & $-2.13 \pm 1.08$ & $-1.66 \pm 1.24$ & $-1.54 \pm 1.24$ & 0.001 \\
GV (cm/yr) & $4.64 \pm 0.80$ & $8.57 \pm 1.49$ & $6.79 \pm 1.26$ & $6.41 \pm 1.54$ & 0.003 \\
IGF-1 SDS & $-1.28 \pm 1.03$ & $-0.18 \pm 0.54$ & $-0.20 \pm 0.77$ & $-0.10 \pm 0.94$ & $<0.001$ \\
IGFBP-3 SDS & $-0.15 \pm 0.40$ & $-0.36 \pm 0.25$ & $-0.16 \pm 0.21$ & $-0.09 \pm 0.34$ & 0.074 \\
BA/CA ratio & $0.62 \pm 0.13$ & $0.68 \pm 0.15$ & $0.79 \pm 0.10$ & $0.86 \pm 0.10$ & 0.001 \\
\hline
\end{tabular}

Values are presented as mean \pm standard deviation.

rhGH, recombinant human growth hormone; CA, chronologic age; BA, bone age; SDS, standard deviation score; GV, growth velocity; IGF1, insulin-like growth factor 1; IGFBP-3, IGF binding protein 3; NA, not available. 
respectively, after 1,2 , and 3 years of treatment and the end of treatment $(P=0.02, P=0.001$, and $P=0.001$, respectively). During treatment, there were no serious adverse events including the cardiac dysfunction, hypertrophic cardiomyopathy, malignancy, hyperglycemia, or thrombocytopenia with bleeding tendency.

\section{Response to rhGH therapy according to genotypes}

The influence of genotype was analyzed by comparing the growth parameters at the start of treatment and 1 year, 2 years, and 3 years after treatment. IGF-1 SDS was significantly different between the group with PTPN11 mutations and the group without PTPN11 mutations at the start of treatment $(P=0.036)$. The other baseline data, including bone age, height SDS, GV, and serum IGFBP-3 levels, were not significantly different between the 2 groups $(P=0.607, P=0.181, P=0.818$, and $P=0.224$, respectively) (Fig. 1). Responses to treatment over 3 years, represented by changes in bone age, GV, serum IGF-1 SDS, and IGFBP-3 SDS, were not significantly different among children with and without mutations in PTPN11 $(P=0.755$, $P=0.864, P=0.113$, and $P=0.145$, respectively). However, height SDS was significantly increased in patients without PTPN11 mutations compared to those with mutations $(P=0.012)$ (Fig. 1).

\section{Discussion}

This paper demonstrated a significant increase in growth parameters, including bone age, height SDS, and IGF-1 SDS in children with NS after 3 years of rhGH therapy. In a previous study with 30 subjects, rhGH therapy increased GV by $2 \mathrm{~cm} /$ yr or more in $80 \%$ of the children after 12 months of rhGH therapy ${ }^{23)}$. Long-term rhGH therapy for 3 years significantly increased height SDS from $-2.7 \pm 0.40$ to $-1.9 \pm 0.9$ in $23 \mathrm{NS}$ children $(P<0.001)$ compared to 8 untreated patients ${ }^{24)}$. However, $\mathrm{GV}$ acceleration was not significant during the second and third years $(P=0.4 \text { and } P=0.5 \text {, respectively })^{24}$.

Several studies have reported the association between PTPN11 mutation and GH resistance by a postreceptor signaling defect ${ }^{25,26)}$. The GH resistance in NS children with PTPN11 mutations may contribute to short stature and their relatively poor response to $\mathrm{rhGH}^{25)}$. Mean $\mathrm{GH}$ levels showed a tendency to be higher in the PTPN11 mutation-positive group $(P=0.075)^{25)}$. However, IGF-1 and IGFBP-3 SDS levels were significantly lower in the PTPN11 mutation-positive group than in the PTPN11 mutation-negative group $(P=0.006)^{25)}$. The improvement of height SDS after 1 year of rhGH therapy was significantly lower in the PTPN11 mutation-positive group $(P=0.007)^{25)}$. In a prospective multicenter study in $35 \mathrm{NS}$ patients, rhGH therapy for 2 years resulted in increased height SDS, which was significantly lower in the PTPN11 mutationpositive group than the PTPN11 mutation-negative group $(P=0.03)^{26}$. Those findings were consistent with a recent study with an animal model showing reduced sensitivity to $\mathrm{GH}$ in PTPN11-mutated mice ${ }^{27}$. In contrast, the response of height SDS to GH treatment for 3.0-10.3 years was not significantly different between patients with or without PTPN11 mutations $(P=0.98)^{16)}$. In the present study, there was a significant difference in height SDS between children with and without PTPN11 mutations after 1, 2 and 3 years of rhGH therapy. GV was significantly different between 2 groups after 1 and 2 years of rhGH therapy. However, GV at third year was not significantly different between 2 groups, suggesting growth response was blunted after long-term rhGH therapy.

Cardiac anomaly is one of the most important characteristics of $\mathrm{NS}^{2)}$. As pulmonary valve stenosis $(30 \%-39 \%)$ and hypertrophic cardiomyopathy $(9.5 \%-30 \%)$ are frequent problems in NS patients, careful monitoring is recommended to detect hypertrophic cardiomyopathy and progression of the underlying heart disease during the period of rhGH treatment ${ }^{28,29)}$. From prospective rhGH trials over 3 years, no children with NS experienced any heart problems based on echocardiography ${ }^{17,30)}$. Two patients have been reported to have mild progression of pulmonary valve stenosis, which was considered to be unrelated to rhGH therapy ${ }^{16)}$. There were no cardiac complications during rhGH therapy in the current study.

In conclusion, long-term rhGH therapy in NS patients was safe and effective at improving height SDS, GV, and serum IGF-1 levels in accordance with previous studies. However, the meticulous monitoring of potential adverse events is still needed because of high dose of rhGH and preexisting hyperactivity of RAS-MAPK pathway. Height SDS in patients without PTPN11mutation was significantly increased compared to those with PTPN11 mutation after 3 years of rhGH therapy.

\section{Conflict of interest}

No potential conflict of interest relevant to this article was reported.

\section{Acknowledgments}

This study was conducted by a grant from the Korean Organization for Rare Diseases.

\section{References}

1. Mendez HM, Opitz JM. Noonan syndrome: a review. Am J Med Genet 1985;21:493-506.

2. Sharland M, Burch M, McKenna WM, Paton MA. A clinical study of Noonan syndrome. Arch Dis Child 1992;67:17883.

3. Tartaglia M, Mehler EL, Goldberg R, Zampino G, Brunner HG, Kremer H, et al. Mutations in PTPN11, encoding the protein tyrosine phosphatase SHP-2, cause Noonan syndrome. Nat Genet 2001;29:465-8.

4. Roberts AE, Araki T, Swanson KD, Montgomery KT, Schiripo TA, Joshi VA, et al. Germline gain-of-function mutations in SOS1 cause Noonan syndrome. Nat Genet 2007;39:70-4.

5. Tartaglia M, Pennacchio LA, Zhao C, Yadav KK, Fodale 
V, Sarkozy A, et al. Gain-of-function SOS1 mutations cause a distinctive form of Noonan syndrome. Nat Genet 2007;39:75-9.

6. Kobayashi T, Aoki Y, Niihori T, Cave H, Verloes A, Okamoto $\mathrm{N}$, et al. Molecular and clinical analysis of RAF1 in Noonan syndrome and related disorders: dephosphorylation of serine 259 as the essential mechanism for mutant activation. Hum Mutat 2010;31:284-94.

7. Lepri FR, Scavelli R, Digilio MC, Gnazzo M, Grotta S, Dentici ML, et al. Diagnosis of Noonan syndrome and related disorders using target next generation sequencing. BMC Med Genet 2014;15:14.

8. Ko JM, Kim JM, Kim GH, Yoo HW. PTPN11, SOS1, KRAS, and RAF1 gene analysis, and genotype-phenotype correlation in Korean patients with Noonan syndrome. J Hum Genet 2008;53:999-1006.

9. Lee BH, Kim JM, Jin HY, Kim GH, Choi JH, Yoo HW. Spectrum of mutations in Noonan syndrome and their correlation with phenotypes. J Pediatr 2011;159:1029-35.

10. Flex E, Jaiswal M, Pantaleoni F, Martinelli S, Strullu M, Fansa EK, et al. Activating mutations in RRAS underlie a phenotype within the RASopathy spectrum and contribute to leukaemogenesis. Hum Mol Genet 2014;23:4315-27.

11. Choi JH, Oh MY, Yum MS, Lee BH, Kim GH, Yoo HW. Moyamoya syndrome in a patient with Noonan-like syndrome with loose anagen hair. Pediatr Neurol 2015; 52:352-5.

12. Gelb BD, Tartaglia M. Noonan syndrome and related disorders: dysregulated RAS-mitogen activated protein kinase signal transduction. Hum Mol Genet 2006;15 Spec No 2:R220-6.

13. Noonan JA. Noonan syndrome and related disorders: alterations in growth and puberty. Rev Endocr Metab Disord 2006;7:251-5.

14. Otten BJ, Noordam C. Growth in Noonan syndrome. Horm Res 2009;72 Suppl 2:31-5.

15. Noonan JA, Kappelgaard AM. The efficacy and safety of growth hormone therapy in children with noonan syndrome: a review of the evidence. Horm Res Paediatr 2015;83:157-66.

16. Noordam C, Peer PG, Francois I, De Schepper J, van den Burgt I, Otten BJ. Long-term GH treatment improves adult height in children with Noonan syndrome with and without mutations in protein tyrosine phosphatase, nonreceptor-type 11. Eur J Endocrinol 2008;159:203-8.

17. Osio D, Dahlgren J, Wikland KA, Westphal O. Improved final height with long-term growth hormone treatment in Noonan syndrome. Acta Paediatr 2005;94:1232-7.

18. Choi JH, Lee BH, Jung CW, Kim YM, Jin HY, Kim JM, et al. Response to growth hormone therapy in children with Noonan syndrome: correlation with or without PTPN11 gene mutation. Horm Res Paediatr 2012;77:388-93.

19. van der Burgt I, Berends E, Lommen E, van Beersum S, Hamel B, Mariman E. Clinical and molecular studies in a large Dutch family with Noonan syndrome. Am J Med Genet 1994;53:187-91.
20. Korea Centers for Disease Control and Prevention, Division of Chronic Disease Surveillance, Committee for the Development of Growth Standard for Korean Children and Adolescents; Korean Pediatric Society, Committee for School Health and Public Health Statistics. 2007 Korean children and adolescents growth standard (commentary for the development of 2007 growth chart). Cheongju: Korea Centers for Disease Control and Prevention, Division of Chronic Disease Surveillance, 2007.

21. Hyun SE, Lee BC, Suh BK, Chung SC, Ko CW, Kim HS, et al. Reference values for serum levels of insulin-like growth factor-I and insulin-like growth factor binding protein-3 in Korean children and adolescents. Clin Biochem 2012;45:16-21.

22. Greulich WW, Pyle SI. Radiographic atlas of skeletal development of the hand and wrist. 2nd ed. Stanford: Stanford University Press, 1959.

23. Cotterill AM, McKenna WJ, Brady AF, Sharland M, Elsawi $M$, Yamada M, et al. The short-term effects of growth hormone therapy on height velocity and cardiac ventricular wall thickness in children with Noonan's syndrome. J Clin Endocrinol Metab 1996;81:2291-7.

24. MacFarlane CE, Brown DC, Johnston LB, Patton MA, Dunger DB, Savage MO, et al. Growth hormone therapy and growth in children with Noonan's syndrome: results of 3 years' follow-up. J Clin Endocrinol Metab 2001;86:19536.

25. Binder G, Neuer K, Ranke MB, Wittekindt NE. PTPN11 mutations are associated with mild growth hormone resistance in individuals with Noonan syndrome. J Clin Endocrinol Metab 2005;90:5377-81.

26. Limal JM, Parfait B, Cabrol S, Bonnet D, Leheup B, Lyonnet $S$, et al. Noonan syndrome: relationships between genotype, growth, and growth factors. J Clin Endocrinol Metab 2006;91:300-6.

27. De Rocca Serra-Nedelec A, Edouard T, Treguer K, Tajan $\mathrm{M}$, Araki T, Dance M, et al. Noonan syndrome-causing SHP2 mutants inhibit insulin-like growth factor 1 release via growth hormone-induced ERK hyperactivation, which contributes to short stature. Proc Natl Acad Sci U S A 2012;109:4257-62.

28. Burch M, Sharland M, Shinebourne E, Smith G, Patton M, McKenna W. Cardiologic abnormalities in Noonan syndrome: phenotypic diagnosis and echocardiographic assessment of 118 patients. J Am Coll Cardiol 1993;22: 1189-92.

29. Marino B, Digilio MC, Toscano A, Giannotti A, Dallapiccola B. Congenital heart diseases in children with Noonan syndrome: An expanded cardiac spectrum with high prevalence of atrioventricular canal. J Pediatr 1999;135:703-6.

30. Noordam C, Draaisma JM, van den Nieuwenhof J, van der Burgt I, Otten BJ, Daniels O. Effects of growth hormone treatment on left ventricular dimensions in children with Noonan's syndrome. Horm Res 2001;56:110-3. 